\title{
The spatial relationship between traffic-related air pollution and noise in two Danish cities: Implications for health-related studies
}

\author{
Jibran Khan $^{\text {a,b,* }}$, Konstantinos Kakosimos ${ }^{c}$, Steen Solvang Jensen ${ }^{\text {a }}$, Ole Hertel ${ }^{\mathrm{a}, \mathrm{b}}$, Mette Sørensen ${ }^{\text {d,e }}$, \\ John Gulliver ${ }^{\mathrm{f}}$, Matthias Ketzel ${ }^{\mathrm{a}, \mathrm{g}}$ \\ a Department of Environmental Science, Aarhus University, Roskilde, Denmark \\ b Danish Big Data Centre for Environment and Health (BERTHA) at Aarhus University, Roskilde, Denmark \\ c Department of Chemical Engineering, Texas AEM University at Qatar, Doha, Qatar \\ d Danish Cancer Society Research Centre, Copenhagen, Denmark \\ e Department of Natural Science and Environment, Roskilde University, Roskilde, Denmark \\ ${ }^{\mathrm{f}}$ Centre for Environmental Health and Sustainability, School of Geography, Geology and the Environment, University of Leicester, Leicester, United Kingdom \\ ${ }^{g}$ Global Centre for Clean Air Research (GCARE), Department of Civil and Environmental Engineering, University of Surrey, Guildford, United Kingdom
}

\section{H I G H L I G H T S}

- Development of a tool to model exposures to air pollution and noise

- Investigation of spatial relationship of air pollution and noise at residential exposure level

- First study to investigate the influence of traffic speed and AADT on air-noise relationship

- First study to compare noise estimates of CNOSSOS and RTN-96 in Denmark

- Overall lower to moderate correlations between levels of air pollution and noise
G R A P H I C A L A B S T R A C T

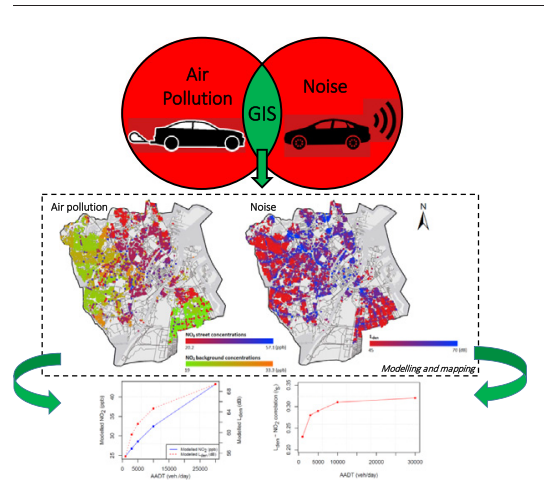

A B S T R A C T

Air pollution and noise originating from urban road traffic have been linked to the adverse health effects e.g. cardiovascular disease (CVD), although their generation and propagation mechanisms vary. We aimed to (i) develop a tool to model exposures to air pollution and noise using harmonized inputs based on similar geographical structure (ii) explore the relationship (using Spearman's rank correlation) of both pollutions at
Received 12 March 2020

Received in revised form 5 April 2020

Accepted 7 April 2020

Available online 11 April 2020

Abbreviations: AADT, Annual average daily traffic; BC, Black Carbon; BioSHARE, Biobank Standardization and Harmonization for Research Excellence in the European Union; CNOSSOS,

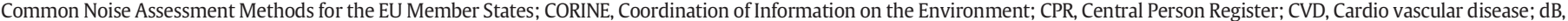

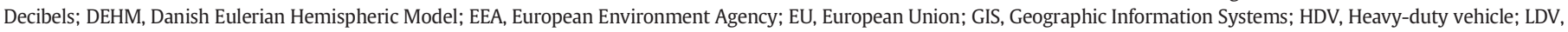

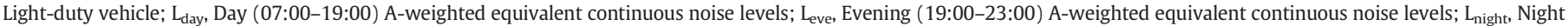

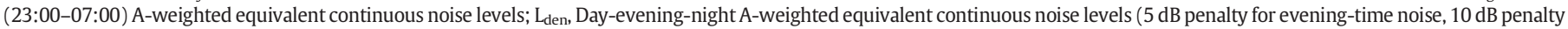

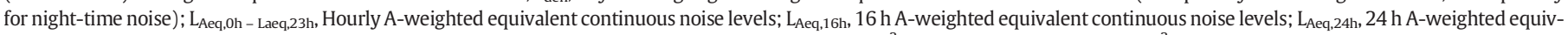

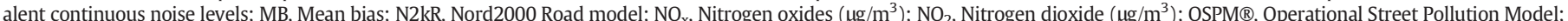

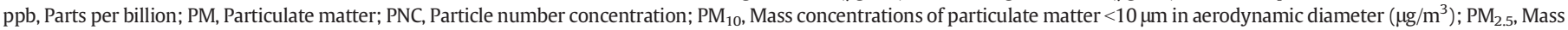

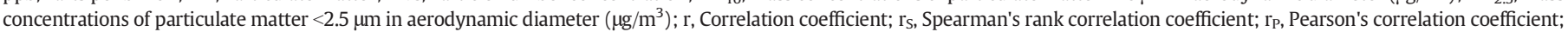

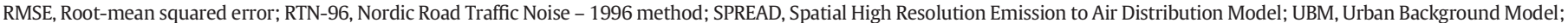
veh/day, Number of vehicles per day; WHO, World Health Organization; WRF, Weather Research and Forecasting Model.

* Corresponding author at: Department of Environmental Science, Aarhus University, DK-4000 Roskilde, Denmark.

E-mail address: jibran@envs.au.dk (J. Khan). 
Editor: Pavlos Kassomenos

Keywords:

Traffic air pollution

Traffic noise

Relationship

CNOSSOS

OSPM ${ }^{\circledR}$

Residential exposure residential exposure level (iii) investigate the influence of traffic speed and Annual Average Daily Traffic (AADT) on air-noise relationship. The annual average (2005) air pollution $\left(\mathrm{NO}_{\mathrm{x}}, \mathrm{NO}_{2}, \mathrm{PM}_{10}, \mathrm{PM}_{2.5}\right)$ and noise levels ( $\mathrm{L}_{\mathrm{day}}$, $\left.\mathrm{L}_{\text {eve, }} \mathrm{L}_{\text {night }}, \mathrm{L}_{\text {den }}, \mathrm{L}_{\text {Aeq,24h }}\right)$ are modelled at address locations in Copenhagen and Roskilde $(N=11,000$ and 1500$)$. The new AirGIS system together with the Operational Street Pollution Model (OSPM $\left.{ }^{\circledR}\right)$ is used to produce air pollution estimates. Whereas, noise is estimated using Common Noise Assessment Methods in the EU (CNOSSOSEU, hereafter CNOSSOS) with relatively coarser inputs (100 m CORINE land cover, simplified vehicle composition). In addition, noise estimates ( $\mathrm{L}_{\mathrm{day}}, \mathrm{L}_{\mathrm{eve}}, \mathrm{L}_{\text {night }}$ ) from CNOSSOS are also compared with noise estimates from Road Traffic Noise 1996 (RTN-96, one of the Nordic noise prediction standards). The overall air-noise correlation structure varied significantly in the range $\left|r_{S}\right|=0.01-0.42$, which was mainly affected by the background concentrations of air pollution as well as non-traffic emission sources. Moreover, neither AADT nor traffic speed showed substantial influence on the air-noise relationship. The noise levels estimated by CNOSSOS were substantially lower, and showed much lower variation than levels obtained by RTN-96. CNOSSOS, therefore, needs to be further evaluated using more detailed inputs (e.g. $10 \mathrm{~m}$ land cover polygons) to assess its feasibility for epidemiological noise exposure studies in Denmark. Lower to moderate air-noise correlations point towards significant potential to determine the independent health effects of air pollution and noise.

(C) 2020 Elsevier B.V. All rights reserved.

\section{Introduction}

Road traffic in urban areas gives rise to both air pollution and noise. According to the European Environment Agency, road traffic is the largest source of noise pollution (EEA, 2017) and contributes significantly to air pollution (e.g. $\mathrm{NO}_{x}, \mathrm{NO}_{2}, \mathrm{PM}_{2.5}$ ) in Europe (EEA, 2016a; EEA, 2019). There is significant and growing evidence linking various health impacts with exposures to air pollution and noise e.g. cardiovascular disease (Cai et al., 2018; Van Kempen et al., 2018), increased blood pressure and hypertension (Pitchika et al., 2017), diabetes (Eze et al., 2017; Van Kempen et al., 2018), morbidity (Zock et al., 2018) and mortality (Mueller et al., 2017; Nieuwenhuijsen et al., 2018). In addition, many researchers (Stansfeld, 2015; Smith et al., 2017) report confounded health effects due to exposure to either air pollution or noise.

There is a growing number of studies (e.g. Allen et al., 2009; Foraster et al., 2011; Khan et al., 2018), which reflect upon the need of more scientific knowledge related to air-noise relationship and their so-called combined exposures. Nevertheless, evaluating the combined exposure of both pollutions is one of the biggest challenges of today (Tenailleau et al., 2016), since tools that facilitate such assessments are not yet available or well known to the scientific community (Khan et al., 2018). Therefore, further research in this context is required to facilitate health-related studies to (i) improve the understanding of combined and/or independent health impacts (ii) adjust for air pollution in noise studies and vice versa.

Few studies (e.g. Tang and Wang, 2007; Davies et al., 2009; Fecht et al., 2016) have quantified the air-noise correlations. In particular, airnoise spatial associations have been explored (e.g. Weber and Litschke, 2008; Allen et al., 2009; Shu et al., 2014) using personal and/or fixedsite monitoring. However, monitoring activities are unavoidably labour intensive as well as expensive, and not suitable for large health-related studies (Nieuwenhuijsen, 2015). Thus, epidemiological studies on city scale $\left(1 \mathrm{~km}^{2}-5000 \mathrm{~km}^{2}\right)$ and/or regional scale $\left(5000 \mathrm{~km}^{2}-10,000 \mathrm{~km}^{2}\right)$ have to rely on residential exposure estimates from ambient pollution dispersion/exposure models (Beelen et al., 2009; Gan et al., 2012; De Roos et al., 2014; Bilenko et al., 2015).

Recently, we conducted a comprehensive review (Khan et al., 2018) of tools and techniques related to air pollution and noise exposure assessment. The review included both modelling and monitoring studies, and showed that air-noise correlation structure $(r=0.05-0.74)$ varies substantially among studies. In addition, several study parameters e.g. traffic attributes such as annual average daily traffic (AADT) (Foraster et al., 2011; Gan et al., 2012), and traffic speed (Shu et al., 2014), building height (Tang and Wang, 2007; Weber et al., 2014), building density (Foraster et al., 2011; Shu et al., 2014), and modelling technique (Khan et al., 2018) have been highlighted to have a direct influence on airnoise relationship. However, how and to what extent these parameters affect relationship of both pollutants has not yet been studied, in detail.
The majority of the health-related studies on noise exposure (e.g. Van Kempen et al., 2017) include air pollution as a confounder, whereas for air pollution studies this is not a standard. Moreover, to our knowledge, little is known about air-noise associations in the Danish context, and no study has been conducted so far explicitly on the spatial relationship of air pollution and noise.

Thus, there are three main objectives of this research work. First, to develop a tool to model exposures to air pollution and noise. Second, to study the correlation between both pollutants and third, to investigate the influence of traffic speed and AADT on air-noise correlations. In this paper, we present results from two case studies in the Danish cities of Copenhagen and Roskilde, as part of our investigation of the relationship between air pollution and noise.

\section{Materials and methods}

This study analysed the spatial relationship of modelled air pollution and noise levels (annual averages, year 2005) at address locations in the Danish cities of Copenhagen (study site $1, N=11,000$ ), and Roskilde (study site $2, N=1500$ ). The following sections describe the study sites, modelling of air pollution and noise, and assessment methodologies.

\subsection{Study sites}

The two study sites (Fig. 1) of Copenhagen and Municipality of Roskilde (hereafter, Roskilde) were chosen as modelled noise estimates from one of the Nordic standards, Road Traffic Noise 1996 (RTN-96) (Jonasson and Nielsen, 1996) (see Section 2.4 for more details), were available for comparison.

Copenhagen is the capital and most populous city of Denmark. As of January 2018, the urban area of Copenhagen as shown in Fig. 1A had a population of 777,218 (502,362 in the year 2005) (Statistics Denmark, 2018). The urban landscape of Copenhagen is dominated by the dense streets and the buildings including major highways (Fig. 1A). Whereas Roskilde (Fig. 1B) as compared to Copenhagen has a significant variation in terms of land cover, i.e. more open areas and less number of buildings and streets. However, some major highways can also be seen here. The city had a population of 50,046 as of 1 January 2016 $(45,807$ in the year 2005) (Statistics Denmark, 2016).

\subsection{Noise model computations}

We modelled A-weighted noise (dB) using CNOSSOS (Kephalopoulos et al., 2012), the European Commission's recommended method for strategic noise mapping, which is mandatory for all EU member states after 31 December 2018 (European Commission, 2016a; Kephalopoulos and Paviotti, 2016). Morley et al. (2015) implemented CNOSSOS noise modelling framework (road module) to produce noise exposure estimation for a 


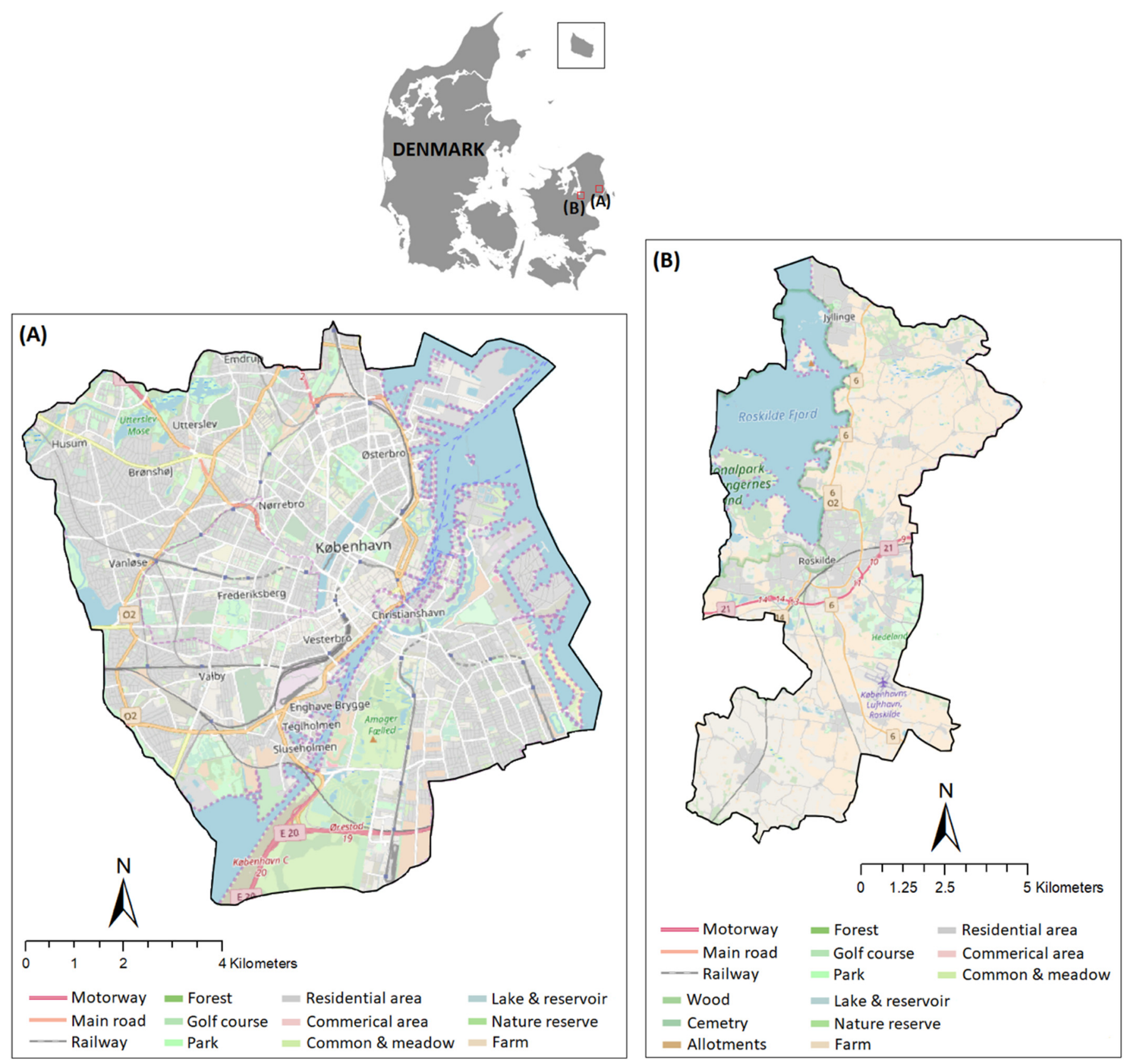

Fig. 1. The location of the two study sites in Denmark: (A) Copenhagen and (B) Roskilde.

(Background map source: OpenStreetMaps).

number of European countries as part of the EU funded BioSHaRE (Biobank Standardization and Harmonization for Research Excellence in the European Union) project (http://www.bioshare.eu/) (e.g. Cai et al., 2017).

Morley et al. (2015) developed and tested six models (A - F) to analyse the importance of data types in terms of noise prediction. Model A contained the highest resolution and most detailed inputs (e.g. OpenStreet MasterMap ${ }^{\circledR}$ as land cover) typically used for city-scale modelling, whereas, model F contained the lowest resolution inputs (e.g. 100 m CORINE land cover) (EEA, 2016b). Moreover, models B - E showed a gradual shift to coarser inputs by degrading the resolution of one input dataset at a time. Models validation showed a strong linear relationship (Spearman's rank: $\mathrm{r}_{\mathrm{s}}=$ 0.74-0.91) for lowest to highest resolution models. Interested readers are referred to Tables 2 and 3, p. 335-336, Morley et al. (2015) for further details.
In this study, mainly due to data availability issues, an approach close to model D is used. That is, the CNOSSOS model algorithm, acquired from Morley et al. (2015), is utilized with AADT (LDV/HDV; there was an option to run with more parameters but these were not available as stated above), buildings footprints with estimated heights, and CORINE land cover. The details regarding model inputs and their sources are as follows.

CNOSSOS requires hourly LDV and HDV values. In Denmark, road traffic information is based on a national road and traffic database in form of a GIS shapefile of road centrelines with most relevant attributes being road width, AADT, HDV share, traffic speed etc. (Jensen et al., 2009). Information on building footprints is available as a polygon shapefile based on a national dataset (Kort10DK), which is obtained from the Danish Geodata Agency (http://gst.dk/). The building footprints include the estimated building height based on national elevation model having $1 \mathrm{~m} \times 1 \mathrm{~m}$ resolution. Geocoded address locations are also obtained from the same agency as a point shapefile. 
The above information was used to prepare input datasets (addresses, road network, building footprints with heights) for CNOSSOS. An automatic script written in open-source software PostgreSQL (hereafter, Postgres) (PostgreSQL Global Development Group, 2018), and hourly traffic composition profiles of the Operational Street Pollution Model (OSPM ${ }^{\circledR}$ ) (Berkowicz, 2000a; Kakosimos et al., 2010) were used to estimate hourly LDV, HDV, and traffic speed for each street. In addition, CORINE land cover data (version 2012), freely available from the European Environment Agency (EEA, 2016b), was used to include several categories of land cover (e.g. urban fabric, open space with little or no vegetation) with a spatial resolution of $100 \mathrm{~m}$.

The CNOSSOS model also takes into accounts for meteorology in terms of an annual average temperature, and a proportion of time in which a receptor is downwind of each source (i.e. in a favourable direction for sound propagation) (Kephalopoulos et al., 2012). These data were derived from the Danish Air Quality Monitoring Programme (Ellermann et al., 2018). Due to relatively small size of study areas (Fig. 1), meteorological conditions (temperature and wind speed) were considered to be the same for all address locations. Furthermore, the CNOSSOS algorithm required address points at $1 \mathrm{~m}$ in front of the building façade. Thus, another Postgres script was used to move all address points (both study sites) from the inside of the building polygons to the required locations.

CNOSSOS has already been tested in some of the Nordic countries; e.g. Finland (Kokkonen et al., 2016; Maijala and Kontkanen, 2016) and Sweden (Larsson, 2016). These studies suggest a few adjustments to CNOSSOS in terms of sound power coefficients, surface corrections etc. for its use in the Nordic countries. Thus, we made three changes in the CNOSSOS script. First, we used sound power coefficients of the standard Nordic noise prediction method i.e. Nord2000 Road (N2kR) (Danish EPA, 2006), instead of the default CNOSSOS coefficients. The Nordic sound power coefficients were taken from Jonasson (2006). It was done to reflect upon the dense asphalt concrete (DAC) road surface conditions as suggested in the literature (see Kragh, 2011 for more details). Second, temperature correction coefficients $(0.10,0.05)$, also obtained from Jonasson (2006), were used instead of the default values. Third, we manually updated the AADT values in the CNOSSOS script for minor roads to 200 vehicles a day. The figure is based on the Danish road and traffic database (Jensen et al., 2009, 2019).

The CNOSSOS model is implemented in Postgres via its spatial extension, PostGIS (PostGIS, 2018). The geometric operations involved in the model algorithms are provided in Morley et al. (2015), and are not described in detail here. In short, through various spatial operations, noise levels at source and receptor (propagation along ray paths) are calculated and logarithmically summed together to produce the final noise estimate.

The annual average hourly noise levels in A-weighted decibels $\left(\mathrm{L}_{\text {Aeq,0h }}-\mathrm{L}_{\text {Aeq,23h }}\right)$ were modelled. A-weighting is the most commonly used frequency weighting (NoiseMeters Inc., 2017), usually denoted by $\mathrm{L}_{\mathrm{A}}$. It covers full audio range $(20 \mathrm{~Hz}$ to $20 \mathrm{kHz}$ ) perceivable by the human ear (IEC 61672-1, 2013; Gracey and Associates, 2017). In addition to above, day-time noise i.e. $\mathrm{L}_{\text {day }}(07: 00-19: 00)$, evening-time noise i.e. $\mathrm{L}_{\text {eve }}(19: 00-23: 00)$, night-time noise i.e. $\mathrm{L}_{\text {night }}(23: 00-07: 00)$, and $\mathrm{L}_{\mathrm{den}}$ (day-evening-night time noise) were estimated. Furthermore, hourly noise levels were averaged to compute A-weighted 24-hourly noise, $L_{\text {Aeq,24h. }} L_{d e n}$ and $L_{\text {night }}$ are the recommended noise metrics to assess health impacts due to noise exposure (European Commission, 2016b). To comply with the European Commission's directives (EC, 2007), the receptor point for noise modelling was at $4 \mathrm{~m}$ above the ground.

\subsection{Air pollution model computations}

The new AirGIS system (Khan et al., 2019) produces input parameters based on national GIS datasets and handles the dataflow in connection with the Operational Street Pollution Model OSPM ${ }^{\circledR}$. AirGIS is the

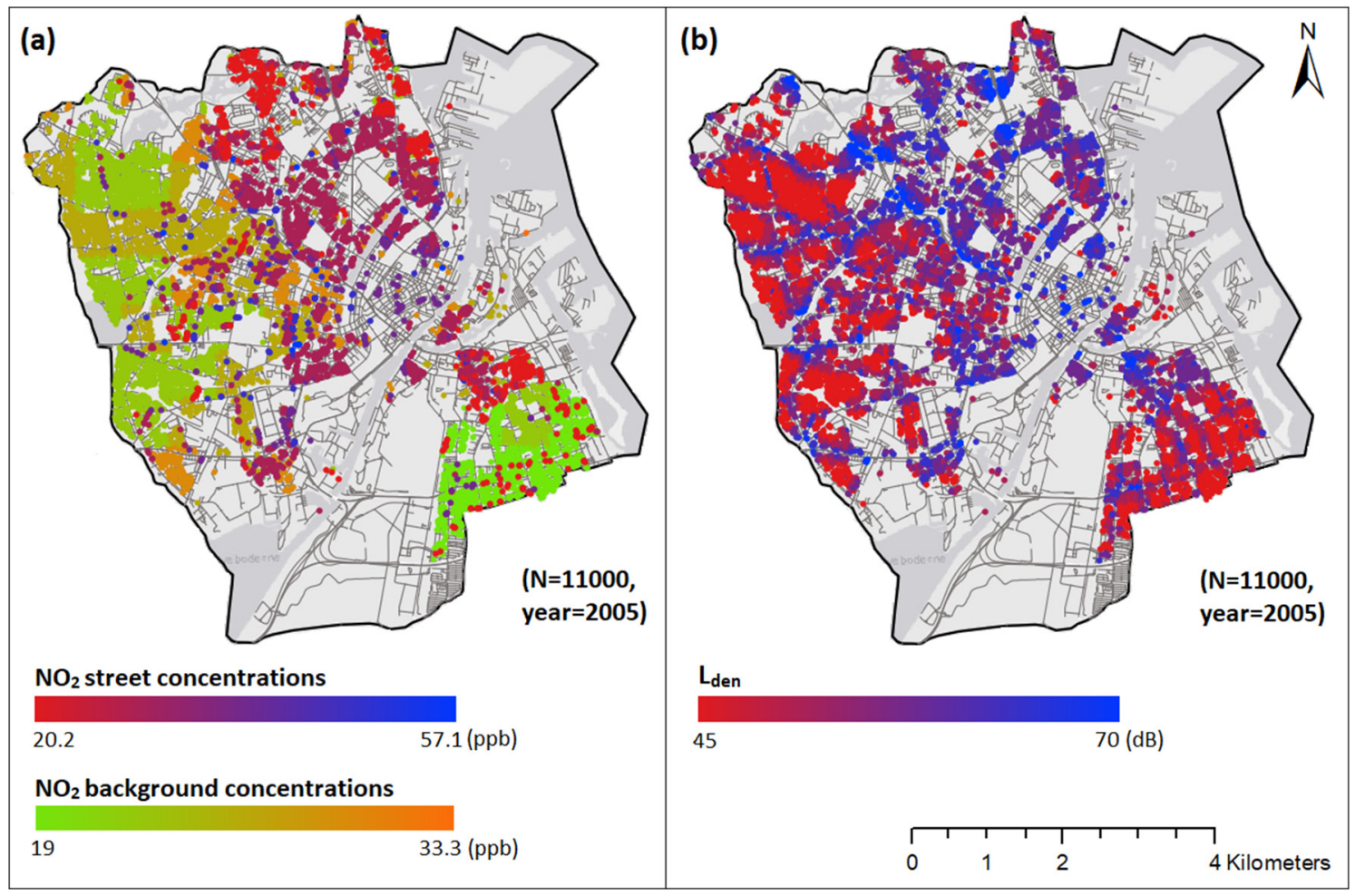

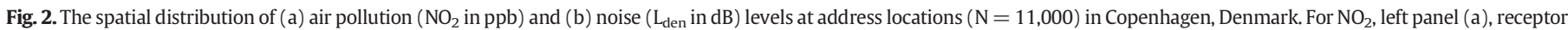

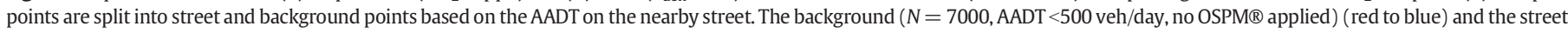

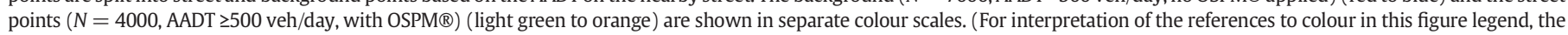
reader is referred to the web version of this article.) 
final part of DEHM/UBM/AirGIS, the Danish multi-scale human exposure modelling system to estimate air pollution concentrations at high spatial (any address location in Denmark) and temporal (hourly) resolution. The modelling system estimates concentrations for many gaseous and particulate pollution components, while this study uses only $\mathrm{NO}_{\mathrm{x}}, \mathrm{NO}_{2}, \mathrm{PM}_{10}$ and $\mathrm{PM}_{2.5}$.

The new AirGIS system is a substantially revised version of the former system (Jensen et al., 2001). In the former system, an Avenue script for ArcView 3.x together with shapefiles for roads, buildings and addresses was used to generate traffic and street configuration inputs for OSPM®. In the new system this has been re-programmed using Postgres database for management of input data, and PostGIS for calculations as well as using R-scripts (R Core Team, 2020) as interface. The comparison of the two systems as well as detailed description of the new system is provided in Khan et al. (2019). Moreover, the new system has been validated in two recent studies for $\mathrm{PM}_{10}, \mathrm{PM}_{2.5}, \mathrm{BC}$ (Hvidtfeldt et al., 2018) and $\mathrm{NO}_{\mathrm{x}}, \mathrm{NO}_{2}, \mathrm{PM}_{10}, \mathrm{PM}_{2.5}$ (Khan et al., 2019). New model validation showed Pearson's correlation coefficient $\left(\mathrm{r}_{\mathrm{P}}\right)$ in the ranges 0.45-0.96 and 0.32-0.92 in terms of reproducing temporal (single location, time-series of concentrations, e.g. annual, daily averages), and spatial (various sites, single time period) variation of the observed air pollution levels. The architecture and operation of the new AirGIS system is briefly summarized in the following sub-section.

The coupled DEHM/UBM/AirGIS system estimates the total concentration for each air pollutant based on three contributions, obtained from a chain of dispersion models containing the Danish Eulerian Hemispheric Model (DEHM), the Urban Background Model (UBM) and the Operational Street Pollution Model (OSPM ${ }^{\circledR}$ ). The DEHM (Christensen, 1997) computes the regional background contributions in a $5.6 \mathrm{~km} \times 5.6 \mathrm{~km}$ grid resolution for Denmark. It is a three-dimensional, offline, Eulerian, longrange atmospheric chemistry transport model developed to study transport of air pollution on the Northern Hemisphere. DEHM takes into account the emissions from all source categories including traffic, industrial units, power plants, small-scale combustion etc. (Brandt et al., 2012).

The UBM (Berkowicz, 2000b) computes the urban background contributions in a resolution of $1 \mathrm{~km} \times 1 \mathrm{~km}$. It is a multiple source model that uses a Gaussian approach for horizontal dispersion and a linear model for vertical dispersion up to the boundary layer. Whereas, the OSPM $®$ computes the street contributions taking the background concentrations from DEHM/UBM as input. OSPM ${ }^{\circledR}$ uses a combination of a plume model for the direct contribution from the traffic source and a box model for the recirculating part of the pollutants inside street

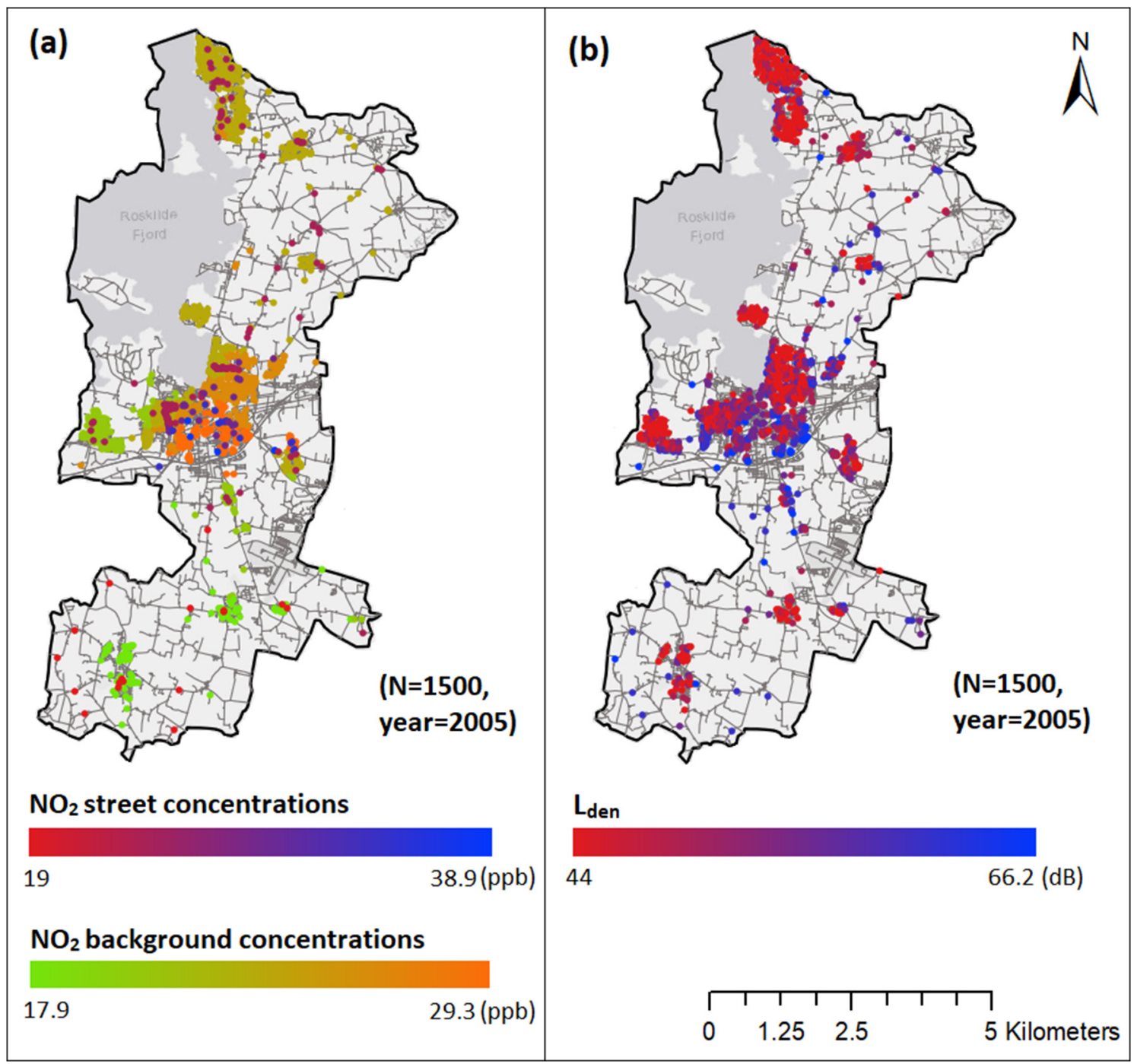

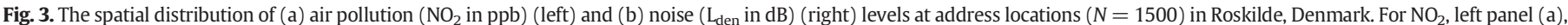

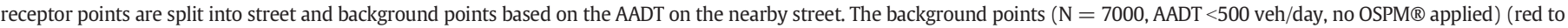

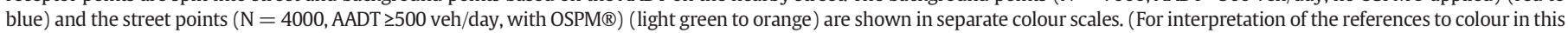
figure legend, the reader is referred to the web version of this article.) 
canyon environment. In case the address is located along roads having AADT $<500 \mathrm{veh} /$ day, only the urban background concentration is assigned. Otherwise, the street pollution model OSPM $®$ is applied additionally to the urban background (also referred as "total" air pollution concentrations).

The emissions database for Denmark, having a high spatial resolution of $1 \mathrm{~km} \times 1 \mathrm{~km}$, is based on the SPREAD methodology (Plejdrup and Gyldenkærne, 2011). The emissions data as well as meteorological datasets (wind direction and speed, air temperature etc.), based on the WRF model (NCAR, 2018), are input to the whole model chain DEHM/UBM/AirGIS.

In terms of GIS inputs, the same road geography and building footprints were used in the noise and air pollution models in order to harmonise input datasets. The GIS input data included address locations with exposure period, streets with traffic attributes (AADT, traffic speed etc.) and buildings with building heights. The detailed working operation of new AirGIS is provided in Khan et al. (2019). In summary, the input data is imported into a Postgres database with its spatial extension, PostGIS that performs all GIS calculations. Subsequently, input files for $O S P M{ }^{\circledR}$ calculations in the required format are produced. Thereafter, OSPM ${ }^{\circledR}$ runs take place to compute street concentrations.

All OSPM ${ }^{\circledR}$ calculations were performed on hourly basis. To maintain synergy with noise calculations, the receptor points were $4 \mathrm{~m}$ above the ground, that is, at the façade of the building closest to the address point. The modelled air pollution concentrations were averaged annually (year 2005), corresponding to the noise model computations.

\subsection{Comparison of RTN-96 and CNOSSOS noise datasets}

In this section, information regarding noise comparison data is summarized.

RTN-96 noise estimated data was obtained for both study sites (same address locations) to compare it with CNOSSOS noise estimates. The RTN-96 (Jonasson and Nielsen, 1996) is one of the Nordic noise prediction standards usually available in SoundPLAN Nordic ${ }^{1}$ software. The dataset including $\mathrm{L}_{\text {day }}$ (07:00-19:00), $\mathrm{L}_{\text {eve }}$ (19:00-22:00) and $\mathrm{L}_{\text {night }}$ (22:00-06:00) (annual averages, year 2005) was acquired from an earlier Danish project (Sørensen et al., 2014). These averaging times (e.g. $\mathrm{L}_{\text {night }}$ ) were slightly different than the CNOSSOS ones described in Section 2.2.

Although, similar GIS data (e.g. road network, building footprints), compared to our noise modelling, was used in noise estimation using RTN-96. The input files used in SoundPLAN software (based on RTN96), however, were not available. Therefore, it was not possible to compare inputs of SoundPLAN and CNOSSOS. Moreover, noise estimates at several building floors using RTN-96 were available, which was not possible in case of CNOSSOS. Consequently, in this study, only ground floor noise estimates of the two noise models are compared. For the ground level, the height of the RTN-96 calculation points was set to $2 \mathrm{~m}$, whereas the height of the CNOSSOS calculation points was set to $4 \mathrm{~m}$ (see Section 2.2). Further details of the two datasets are provided in Supplementary material (Appendix A).

\subsection{Spatial and statistical analyses}

We used Spearman's correlation coefficients $\left(r_{S}\right)$ to explore the space and time correlation between modelled air pollution $\left(\mathrm{NO}_{\mathrm{x}}, \mathrm{NO}_{2}\right.$, $\left.\mathrm{PM}_{10}, \mathrm{PM}_{2.5}\right)$ and noise $\left(\mathrm{L}_{\text {day }}, \mathrm{L}_{\text {eve }}, \mathrm{L}_{\text {night }}, \mathrm{L}_{\mathrm{den}}, \mathrm{L}_{\text {Aeq,24h }}\right)$ metrics, separating background points ( $<500 \mathrm{veh} /$ day) and street/OSPM ${ }^{\circledR}$ points ( $\geq 500 \mathrm{veh} /$ day). Correlations of background and total (street + background) air pollution with noise were computed to analyse how noise correlate with the urban background and the street levels of air pollution. In addition, the Pearson's correlations $\left(\mathrm{r}_{\mathrm{P}}\right)$ are computed and

\footnotetext{
1 See: http://soundplan.dk/.
}

Table 1

Spearman's correlation coefficients of noise and total air pollution (street sites: $N=4000, \geq 500 \mathrm{veh} /$ day) and background air pollution (background sites: $N=7000$ $<500$ veh/day) in Copenhagen, Denmark. All correlations are statistically significant $(\mathrm{p}<0.001) . \mathrm{NO}_{\mathrm{x}}$ and $\mathrm{NO}_{2}$ are given in $\mathrm{ppb}$ while $\mathrm{PM}_{10}, \mathrm{PM}_{2.5}$ in $\mu \mathrm{g} / \mathrm{m}^{3}$. All noise metrics are given in $\mathrm{dB}$.

\begin{tabular}{|c|c|c|c|c|c|c|c|c|c|}
\hline & \multicolumn{5}{|c|}{ Noise } & \multicolumn{4}{|c|}{ Air pollutants } \\
\hline & $\mathrm{L}_{\text {day }}$ & $\mathrm{L}_{\text {eve }}$ & $\mathrm{L}_{\text {night }}$ & $\mathrm{L}_{\mathrm{den}}$ & $\mathrm{L}_{\mathrm{Aeq}, 24 \mathrm{~h}}$ & $\mathrm{NO}_{\mathrm{x}}$ & $\mathrm{NO}_{2}$ & $\mathrm{PM}_{10}$ & $\mathrm{PM}_{2.5}$ \\
\hline \multicolumn{10}{|c|}{ Street sites in Copenhagen } \\
\hline $\mathrm{L}_{\text {day }}$ & - & 0.99 & 0.99 & 0.99 & 0.99 & 0.41 & 0.42 & 0.27 & 0.24 \\
\hline $\mathrm{L}_{\text {eve }}$ & & - & 0.99 & 0.99 & 0.99 & 0.40 & 0.41 & 0.27 & 0.23 \\
\hline $\mathrm{L}_{\text {night }}$ & & & - & 0.99 & 0.99 & 0.38 & 0.39 & 0.25 & 0.23 \\
\hline $\mathrm{L}_{\mathrm{den}}$ & & & & - & 0.99 & 0.39 & 0.41 & 0.27 & 0.24 \\
\hline $\mathrm{L}_{\text {Aeq, } 24 \mathrm{~h}}$ & & & & & - & 0.41 & 0.42 & 0.27 & 0.25 \\
\hline $\mathrm{NO}_{\mathrm{x}}$ & & & & & & - & 0.95 & 0.76 & 0.68 \\
\hline $\mathrm{NO}_{2}$ & & & & & & & - & 0.71 & 0.66 \\
\hline $\mathrm{PM}_{10}$ & & & & & & & & - & 0.98 \\
\hline $\mathrm{PM}_{2.5}$ & & & & & & & & & - \\
\hline \multicolumn{10}{|c|}{ Background sites in Copenhagen } \\
\hline $\mathrm{L}_{\text {day }}$ & - & 0.99 & 0.99 & 0.99 & 0.99 & 0.35 & 0.35 & 0.05 & 0.03 \\
\hline $\mathrm{L}_{\text {eve }}$ & & - & 0.99 & 0.99 & 0.99 & 0.35 & 0.36 & 0.05 & 0.03 \\
\hline $\mathrm{L}_{\text {night }}$ & & & - & 0.99 & 0.99 & 0.34 & 0.34 & 0.06 & 0.04 \\
\hline$L_{\text {den }}$ & & & & - & 0.99 & 0.35 & 0.35 & 0.06 & 0.04 \\
\hline $\mathrm{L}_{\text {Aeq,24h }}$ & & & & & - & 0.35 & 0.34 & 0.05 & 0.03 \\
\hline $\mathrm{NO}_{\mathrm{x}}$ & & & & & & - & 0.99 & 0.57 & 0.50 \\
\hline $\mathrm{NO}_{2}$ & & & & & & & - & 0.58 & 0.52 \\
\hline $\mathrm{PM}_{10}$ & & & & & & & & - & 0.99 \\
\hline $\mathrm{PM}_{2.5}$ & & & & & & & & & - \\
\hline
\end{tabular}

provided in Supplementary material. To compare CNOSSOS and RTN96 noise estimates, several statistical measures i.e. minimum (Min), maximum (Max), median (Med), root-mean-squared error (RMSE), mean bias (MB), normalized mean bias (NMB) are computed. The definitions of the statistical measures are provided in Supplementary material (Appendix B). All statistical analyses were performed in R software version 3.6.2.

\subsection{Parameters affecting air-noise correlations}

As an innovative part of this research work, we studied the influence of selected study parameters on air-noise correlation. These parameters, which included AADT and traffic speed, are used to perform sensitivity

Table 2

Spearman's correlation coefficients of noise and total air pollution (street sites: $N=200$, $\geq 500 \mathrm{veh} /$ day) and background air pollution (background sites: $N=1300,<500 \mathrm{veh} /$ day) in Roskilde, Denmark. All correlations are statistically significant $(\mathrm{p}<0.001)$. NO and $\mathrm{NO}_{2}$ are given in ppb while $\mathrm{PM}_{10}, \mathrm{PM}_{2.5} \mathrm{in} \mu \mathrm{g} / \mathrm{m}^{3}$. All noise metrics are given in $\mathrm{dB}$.

\begin{tabular}{|c|c|c|c|c|c|c|c|c|c|}
\hline & \multicolumn{5}{|c|}{ Noise } & \multicolumn{4}{|c|}{ Air pollutants } \\
\hline & $\mathrm{L}_{\text {day }}$ & Leve & $\mathrm{L}_{\text {night }}$ & $\mathrm{L}_{\text {den }}$ & $\mathrm{L}_{\mathrm{Aeq}, 24 \mathrm{~h}}$ & $\mathrm{NO}_{\mathrm{x}}$ & $\mathrm{NO}_{2}$ & $\mathrm{PM}_{10}$ & $\mathrm{PM}_{2.5}$ \\
\hline \multicolumn{10}{|c|}{ Street sites in Roskilde } \\
\hline $\mathrm{L}_{\text {day }}$ & - & 0.99 & 0.99 & 0.99 & 0.99 & 0.27 & 0.14 & -0.02 & -0.13 \\
\hline Leve & & - & 0.99 & 0.99 & 0.99 & 0.26 & 0.13 & -0.04 & -0.14 \\
\hline $\mathrm{L}_{\text {night }}$ & & & - & 0.99 & 0.99 & 0.27 & 0.16 & -0.02 & -0.12 \\
\hline $\mathrm{L}_{\mathrm{den}}$ & & & & - & 0.99 & 0.26 & 0.16 & -0.02 & -0.13 \\
\hline $\mathrm{L}_{\text {Aeq, } 24 \mathrm{~h}}$ & & & & & - & 0.27 & 0.15 & -0.01 & -0.12 \\
\hline NOx & & & & & & - & 0.97 & 0.77 & 0.66 \\
\hline $\mathrm{NO}_{2}$ & & & & & & & - & 0.82 & 0.70 \\
\hline $\mathrm{PM}_{10}$ & & & & & & & & - & 0.92 \\
\hline $\mathrm{PM}_{2.5}$ & & & & & & & & & - \\
\hline \multicolumn{10}{|c|}{ Background sites in Roskilde } \\
\hline $\mathrm{L}_{\text {day }}$ & - & 0.99 & 0.99 & 0.99 & 0.99 & 0.27 & 0.27 & -0.02 & -0.13 \\
\hline $\mathrm{L}_{\text {eve }}$ & & - & 0.99 & 0.99 & 0.99 & 0.26 & 0.26 & -0.03 & -0.14 \\
\hline $\mathrm{L}_{\text {night }}$ & & & - & 0.99 & 0.99 & 0.27 & 0.28 & -0.01 & -0.13 \\
\hline $\mathrm{L}_{\mathrm{den}}$ & & & & - & 0.99 & 0.27 & 0.28 & -0.02 & -0.14 \\
\hline $\mathrm{L}_{\mathrm{Aeq}, 24 \mathrm{~h}}$ & & & & & - & 0.26 & 0.27 & -0.01 & -0.13 \\
\hline $\mathrm{NO}_{\mathrm{x}}$ & & & & & & - & 0.99 & 0.64 & 0.55 \\
\hline $\mathrm{NO}_{2}$ & & & & & & & - & 0.64 & 0.54 \\
\hline $\mathrm{PM}_{10}$ & & & & & & & & - & 0.87 \\
\hline $\mathrm{PM}_{2.5}$ & & & & & & & & & - \\
\hline
\end{tabular}




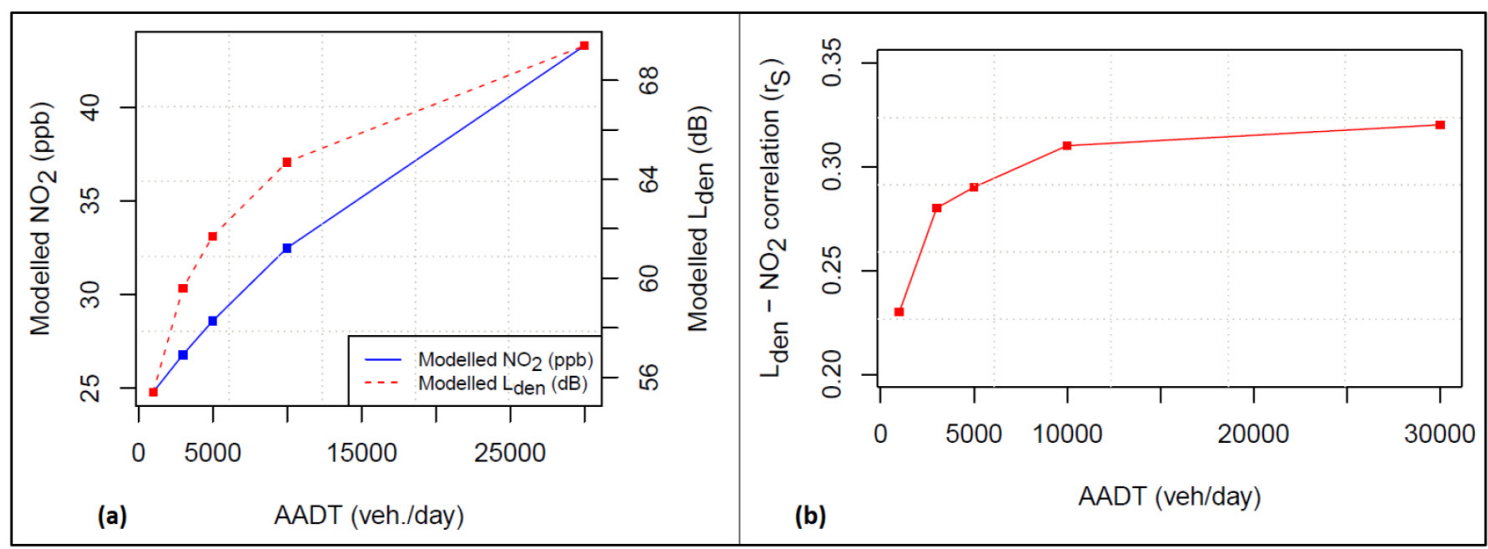

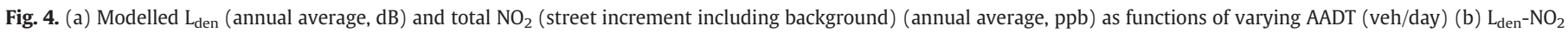

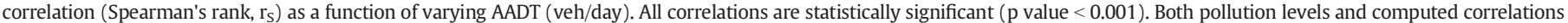
are for the fixed traffic speed $=40 \mathrm{~km} / \mathrm{h}$ in Copenhagen $(\mathrm{N}=11,000$, year 2005).

analyses on the air-noise relationship. Due to the large number of address locations $(N=11,000)$, we conducted these separate analyses (test cases) only for the Copenhagen site. These analyses were supplemented by several parallel DEHM/UBM/AirGIS and CNOSSOS model runs. Details are summarized in the following sub-section.

\subsubsection{AADT and traffic speed}

Five test cases were selected based on AADT in the range 1000-30,000 veh/day. For each case (e.g. 1000 veh/day), the same AADT was assigned to all roads in the study area, and traffic speed was set to $40 \mathrm{~km} / \mathrm{h}$. Subsequently, air $\left(\mathrm{NO}_{2}\right)$ and noise pollution $\left(\mathrm{L}_{\mathrm{den}}\right)$ calculations (annual average, year 2005) were performed for all the cases. The Spearman's correlation coefficients of background and street levels of air pollution $\left(\mathrm{NO}_{2}\right)$ with the corresponding noise $\left(\mathrm{L}_{\mathrm{den}}\right)$ levels were computed. The correlations were plotted against AADT values to analyse its influence on air-noise relationship.

Likewise, five cases of traffic speed in the range $40-80 \mathrm{~km} / \mathrm{h}$ were defined. For each case, same traffic speed was assigned to the whole road network, and AADT was set to $10,000 \mathrm{veh}$ /day. Air pollution and noise $\left(\mathrm{NO}_{2}\right.$ and $\left.\mathrm{L}_{\mathrm{den}}\right)$ levels were calculated (annual averages, year 2005) for all cases. Finally, correlation coefficients were computed and plotted against the traffic speed to study its effect on air-noise association.

\section{Results and discussions}

\subsection{Air-noise correlations}

This section presents the results of spatial distribution of both pollution levels at address locations $(N=11,000$ and 1500) in the Danish cities of Copenhagen and Roskilde. In addition, air-noise correlations are also presented and discussed.

Figs. 2 and 3 show the spatial patterns of modelled noise $\left(L_{d e n}\right.$ in $\left.d B\right)$ and air pollution $\left(\mathrm{NO}_{2}\right.$ in ppb) levels in Copenhagen and Roskilde. In terms of $\mathrm{NO}_{2}$ (Figs. 2a and 3a), street points ( $\geq 500$ veh/day) and background points ( $<500 \mathrm{veh} /$ day) are shown separately. Let us recall, the street and the background air pollution concentrations are combined (total air pollution) when AADT $\geq 500 \mathrm{veh} /$ day (see Section 2.3). In both study sites (Figs. 2 and 3), modelled $\mathrm{L}_{\text {den }}$ and $\mathrm{NO}_{2}$ levels are higher determined by the promixity to the major roads, and vary generally smoothly close to the minor/less busy roads. Same spatial patterns were observed for other air pollution and noise metrics. The estimated noise (e.g. $\mathrm{L}_{\mathrm{den}}$ : 44-66.2 dB) in Roskilde, however, was generally lower than the ones (e.g. $\mathrm{L}_{\mathrm{den}}$ : $45-70 \mathrm{~dB}$ ) in Copenhagen. This is due to more number of less busy roads in Roskilde.

Tables 1 and 2 show Spearman's rank correlations $\left(r_{S}\right)$ among various air pollutants and noise at street sites ( $\geq 500 \mathrm{veh} /$ day, "total" air pollution and noise), and background sites ( $<500 \mathrm{veh} /$ day, background air

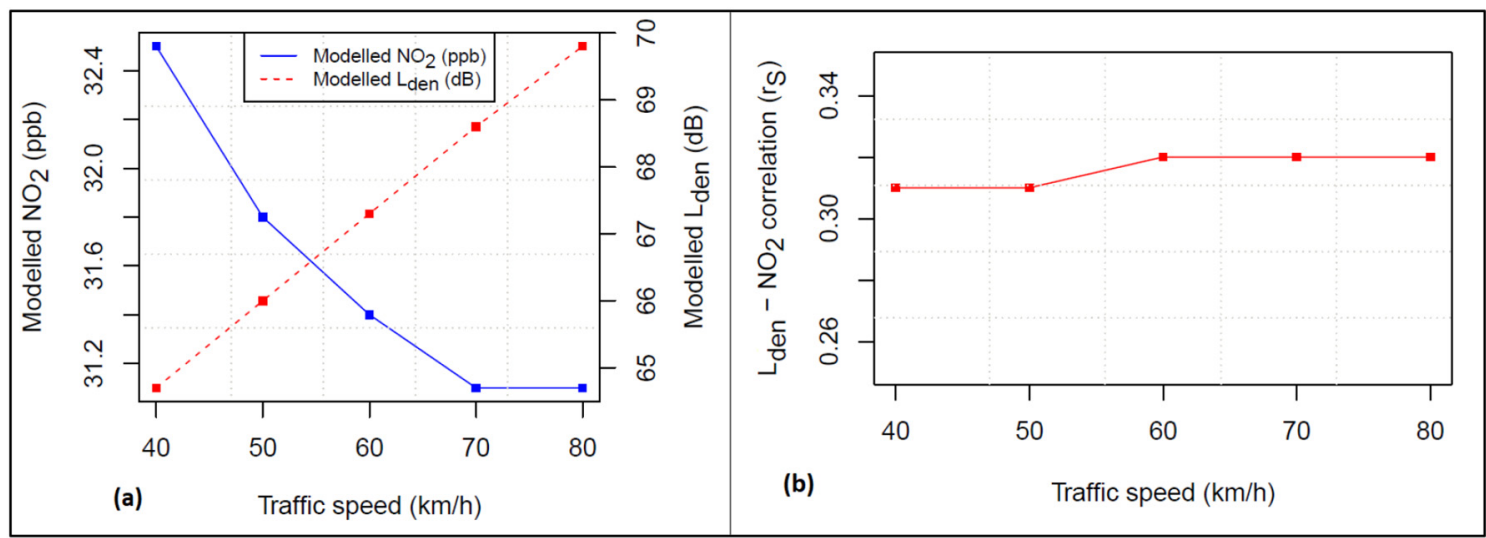

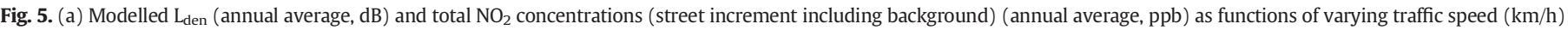

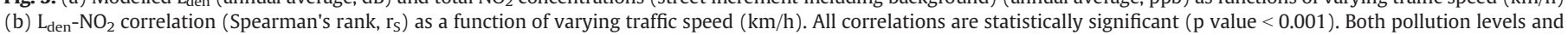
computed correlations are for the fixed AADT $=10,000 \mathrm{veh} /$ day in Copenhagen $(N=11,000$, year 2005). 
pollution and noise) in Copenhagen and Roskilde. Pearson's correlations $\left(\mathrm{r}_{\mathrm{P}}\right)$ are provided in Supplementary Tables S1 and S2, Appendix C. All computed correlations (Tables 1,2 and S1, S2) are statistically significant ( $\mathrm{p}$ value $<0.001$ ). The intra-class correlations (Table 1 , both street and background sites in Copenhagen) were very strong for noise metrics $\left(r_{\mathrm{S}}=0.99\right)$; varied significantly for air pollutants (overall $\mathrm{r}_{\mathrm{S}}=$ $0.50-0.99)$. Moreover, both $\mathrm{PM}_{10}$ and $\mathrm{PM}_{2.5}\left(\mu \mathrm{g} / \mathrm{m}^{3}\right)$ correlated poorly $\left(\mathrm{r}_{\mathrm{S}}=0.27\right.$ and $\left.\mathrm{r}_{\mathrm{S}}=0.24\right)$ with $\mathrm{L}_{\mathrm{den}}$ at street sites (Table 1$)$, and didn't show any association $\left(r_{S}=0.04-0.06\right)$ with $L_{d e n}$ at background sites. Same correlation patterns were observed between other noise metrics and $\mathrm{PM}_{10}, \mathrm{PM}_{2.5}$.

The correlations between $\mathrm{NO}_{\mathrm{x}}$ and $\mathrm{NO}_{2}(\mathrm{ppb})$ and $\mathrm{L}_{\mathrm{den}}$, at both street and background sites, were moderate with overall range $r_{S}=0.35$ to
$\mathrm{r}_{\mathrm{S}}=0.41$ (Table 1). Vardoulakis et al. (2003) reported that the roadside air pollution concentrations usually consist of two components, the persistent urban background levels and the direct vehicle emissions. Hence, above moderate correlations highlight the background levels of air pollution as one of the key drivers of air-noise relationship, especially in the urban settings. The same was reported by King et al. (2016), who performed combined assessment of both pollutions in New York, the United States.

In Roskilde (Table 2, both street and background sites), the associations were again strong between the different noise metrics $\left(r_{S}=0.99\right)$; varied significantly among air pollutants (overall $r_{S}=0.54-0.99$ ). Here, $\mathrm{PM}_{10}$ and $\mathrm{PM}_{2.5}$ correlated negatively $\left(\mathrm{r}_{\mathrm{S}}=-0.02\right.$ to $\mathrm{r}_{\mathrm{S}}=-0.14$, Table 2) with $\mathrm{L}_{\mathrm{den}}$. In addition, correlations between $\mathrm{NO}_{\mathrm{x}}, \mathrm{NO}_{2}$ (street

\section{Copenhagen}
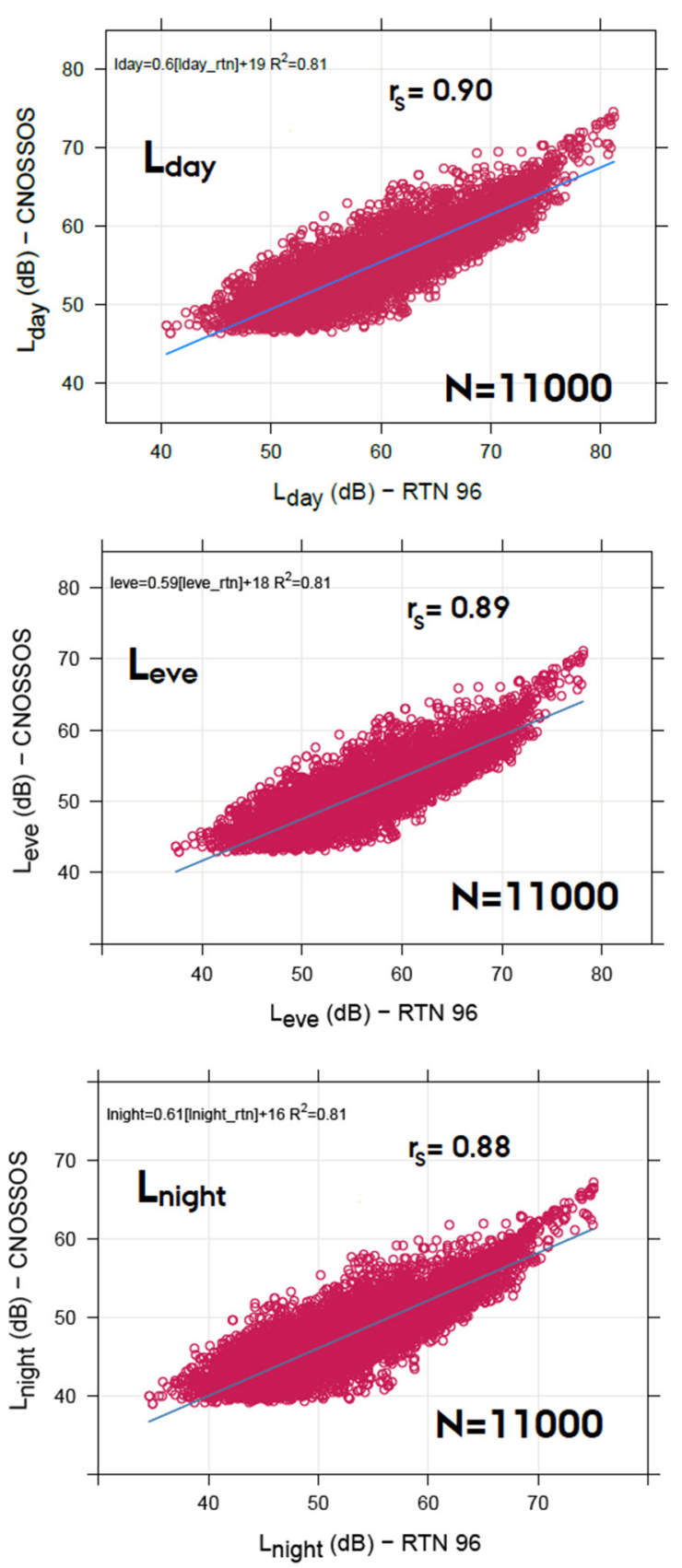

\section{Roskilde}
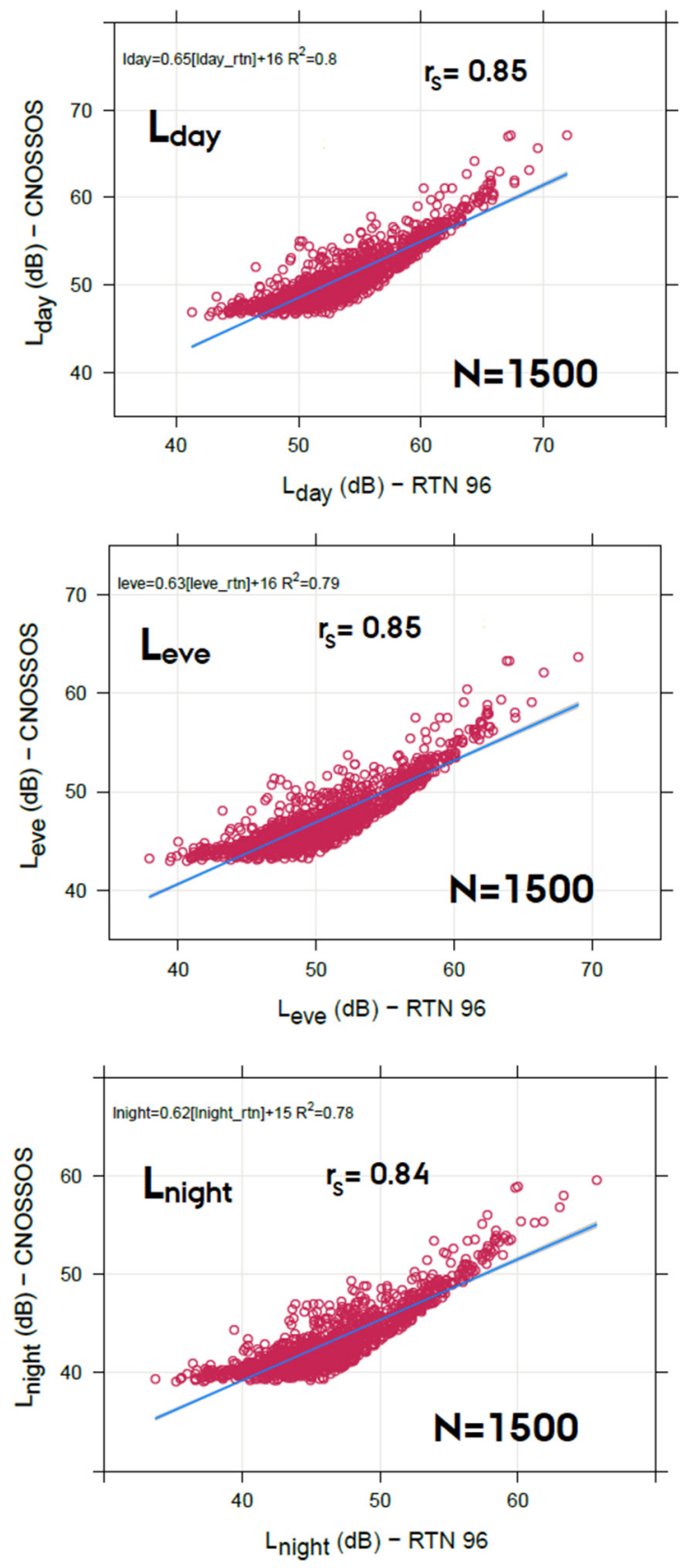

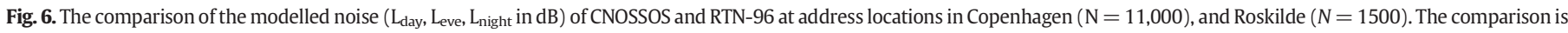

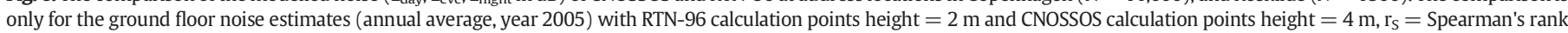
correlation coefficient. 
and background concentrations) and $\mathrm{L}_{\mathrm{den}}$ were generally lower $\left(\mathrm{r}_{\mathrm{S}}=\right.$ 0.16 to $r=0.28$ ) than those for Copenhagen. This is, again, mainly due to more number of less busy roads in Roskilde. Similar patterns of correlations were observed among other noise metrics and air pollutants (Table 2).

The air-noise correlations in our study (Tables 1 and 2) generally seem to be lower to moderate. Lower to moderate correlations (contra high correlations) however are an advantage, if one wants to separate the effect of air pollution and noise in epidemiological studies. Similar air-noise associations have previously been documented. Linares et al. (2006) reported noise- $\mathrm{NO}_{\mathrm{x}}, \mathrm{NO}_{2}$ correlation in the range 0.14-0.20. Gan et al. (2012) reported weak correlation $(r=0.14)$ between $\mathrm{PM}_{2.5}$ $\left(\mu \mathrm{g} / \mathrm{m}^{3}\right)$ and noise. Both above studies were based on measurements of pollution. Tobías et al. (2001) reported moderate noise- $\mathrm{NO}_{2}$ associations $(r=0.32)$ in their work. Fecht et al. (2016) also reported moderate noise-PM correlations in the range 0.41-0.53; their analyses were based on various geographical units (Postcode level, census areas etc.), and did not distinguish between street and background levels of air pollution.

In addition to above, higher air-noise correlations have also been reported. Sørensen et al. (2014) found Pearson's correlations $r_{P}=0.62$ $\left(\mathrm{NO}_{2}\right.$ and $\left.\mathrm{L}_{\mathrm{den}}\right)$ and $\mathrm{r}_{\mathrm{P}}=0.66\left(\mathrm{NO}_{\mathrm{x}}\right.$ and $\left.\mathrm{L}_{\mathrm{den}}\right)$, and Pyko et al. (2017) reported $r=0.56$ between $\mathrm{NO}_{\mathrm{x}}$ and $\mathrm{L}_{\mathrm{den}}$ in their work. Furthermore, examples of negative air-noise correlation can also be seen in the literature. Shu et al. (2014) reported negative to lower positive PMnoise correlations $(-0.36-0.12)$, however, none of the correlations was statistically significant. Likewise, Weber (2009) reported negative correlations (Pearson's: -0.18 and Spearman's: -0.21 , not significant for $\mathrm{p}<0.05$ ) between total PNC and noise.

Differences in our modelled air pollution and noise levels and subsequently, their correlations are due to the following reasons. First, for address locations close to the major highways (both Copenhagen and Roskilde), estimated noise was high and air pollution was low (see Fig. S1, Appendix D). Reason being OSPM ${ }^{\circledR}$ does not take into account the contributions from highways as OSPM ${ }^{\circledR}$ calculates for the specific street in question and contribution from highway sources are only indirectly modelled thorough background concentrations (Jensen et al., 2017). This issue is described in detail in Appendix D, Supplementary material. Second, some address locations in Roskilde were close to non-traffic emission sources (wood burning, industrial field etc.). In particular, due to wood burning, there was elevated modelled background PM as compared to low noise levels (see Figs. S2 and S3, Appendix D), which caused low and negative correlations (Table 2). Third, the use of coarser CORINE land cover data may have affected CNOSSOS performance to an unknown extent, which could also contribute to lower airnoise correlations. CNOSSOS, therefore, needs to be further tested with detailed land cover data (once available) in future air-noise assessments.

\subsection{Parameters affecting correlations}

This section evaluates the influence of AADT and traffic speed on airnoise correlations. The results presented here are based on separate assessments (test cases) conducted only in Copenhagen $(N=11,000$; annual averages of pollutions, year 2005) (see Section 2.6).

\subsubsection{Influence of $A A D T$ and traffic speed}

Figs. 4 and 5 show modelled ( $N=11,000$, annual averages, year 2005) $\mathrm{NO}_{2}$ and $\mathrm{L}_{\mathrm{den}}$ as well as their correlation (Spearman's rank, $\mathrm{r}_{\mathrm{S}}$ ) as functions of increasing AADT and traffic speed. As expected, $\mathrm{L}_{\mathrm{den}}$ increased logarithmically with the increase of AADT (Fig. 4), and linearly with the increase of speed (Fig. 5). $\mathrm{NO}_{2}$ increased linearly with AADT, but decreased with speed in the examined speed interval of $40-80 \mathrm{~km} / \mathrm{h}$. The latter was, probably, due to the dependence of $\mathrm{NO}_{\mathrm{x}}$ emissions on the vehicle speed. In addition, the $\mathrm{L}_{\mathrm{den}}-\mathrm{NO}_{2}$ correlation changed from $r_{S}=0.23$ to $r_{S}=0.32$ with the increase of AADT (1000-30,000 veh/day); it remained nearly constant with respect to increasing speed $(40-80 \mathrm{~km} / \mathrm{h})$. Due to lack of similar studies, it was not possible to compare our findings with the existing literature.

\subsection{Modelled noise: CNOSSOS vs RTN-96}

Fig. 6 shows the comparison of annual average (2005) modelled noise ( $\mathrm{L}_{\text {day }}, \mathrm{L}_{\text {eve }}, \mathrm{L}_{\text {night }}$ in $\mathrm{dB}$ ) from CNOSSOS and RTN-96 at address locations in Copenhagen and Roskilde ( $\mathrm{N}=11,000$ and 1500). Table 3 presents the summary statistics of the modelled noise at same addresses. A strong overall correlation (range $r_{S}=0.84-0.90$ ) can be seen between the modelled noise of CNOSSOS and RTN-96 (Fig. 6). In addition, a few notable outliers can also be observed.

There was a significant difference and lower variation in the estimated noise of CNOSSOS (e.g. RMSE: 3.4-6 dB, Table 3) as compared to RTN-96 both in Copenhagen and Roskilde (see Table 3, and Supplementary Fig. S4, Appendix E). It has not been possible to fully explain these differences between RTN-96 and CNOSSOS. One limitation has been the missing access to the input data to the RTN-96 calculations. A number of reasons may be speculated to explain the observed differences. CNOSSOS was run with coarser CORINE land cover and simplified vehicle composition (LDV, HDV) as inputs. Moreover, a difference exists in the heights of the calculation points of the two models (CNOSSOS: $4 \mathrm{~m}$, RTN-96: $2 \mathrm{~m}$ ), and small differences in the time-averaging of $\mathrm{L}_{\mathrm{eve}}$ and $\mathrm{L}_{\text {night }}$.

Furthermore, CNOSSOS modelled noise at one single point (address location) at a time, whereas, RTN-96, for each address location, modelled noise by taking into account the maximum of all façade points (see Section 2.4 and Appendix A, Supplementary). However, lower variation in CNOSSOS estimated noise compared to RTN-96 indicates some exposure misclassifications. Such exposure misclassifications due to relatively course input data has been found to be problematic in relation to estimation of impacts on health such as myocardial infarction mortality (Vienneau et al., 2019). Therefore, further testing and evaluation of CNOSSOS with detailed inputs is necessary before it may be used for noise exposure assessments in Denmark.

Table 3

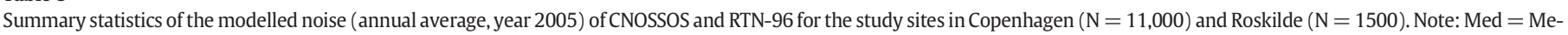

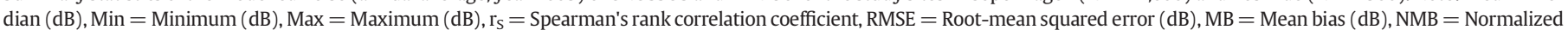
mean bias.

\begin{tabular}{|c|c|c|c|c|c|c|c|c|c|c|}
\hline & \multicolumn{3}{|c|}{ RTN-96 } & \multicolumn{3}{|c|}{ CNOSSOS } & \multirow[t]{2}{*}{ RMSE } & \multirow[t]{2}{*}{$\mathrm{MB}$} & \multirow[t]{2}{*}{ NMB } & \multirow[t]{2}{*}{ Correlation $\left(\mathrm{r}_{\mathrm{S}}\right)$} \\
\hline & Min & Max & Med & Min & Max & Med & & & & \\
\hline \multicolumn{11}{|c|}{ Copenhagen } \\
\hline $\mathrm{L}_{\text {day }}(\mathrm{dB})$ & 40.4 & 81.2 & 59.8 & 46.3 & 74.6 & 54.8 & 5.4 & -4.1 & -0.07 & 0.90 \\
\hline Leve $(\mathrm{dB})$ & 37.3 & 78.1 & 56.4 & 42.8 & 71 & 50.9 & 6 & -4.9 & -0.08 & 0.89 \\
\hline $\mathrm{L}_{\text {night }}(\mathrm{dB})$ & 34.5 & 75 & 52.5 & 38.9 & 67.1 & 47.1 & 5.9 & -4.8 & -0.09 & 0.88 \\
\hline \multicolumn{11}{|l|}{ Roskilde } \\
\hline $\mathrm{L}_{\mathrm{day}}(\mathrm{dB})$ & 41.3 & 71.9 & 52.5 & 46.4 & 67.1 & 49.7 & 3.4 & -2.6 & -0.05 & 0.85 \\
\hline $\mathrm{L}_{\text {eve }}(\mathrm{dB})$ & 37.9 & 69 & 49.2 & 42.9 & 63.6 & 45.8 & 3.8 & -3.1 & -0.06 & 0.85 \\
\hline $\mathrm{L}_{\text {night }}(\mathrm{dB})$ & 33.7 & 65.7 & 45.4 & 39 & 59.5 & 41.9 & 3.8 & -3.1 & -0.06 & 0.84 \\
\hline
\end{tabular}




\section{Strengths and limitations}

This study explicitly explores the spatial relationship of air pollution and noise at residential addresses in Denmark, and investigates the influence of selected parameters on this relationship. Moreover, the use of harmonized input data based on the similar geographical structure led to the development of a tool to model both exposures at the same time. This is particularly important because published literature (e.g. European Commission, 2016c; Khan et al., 2018) highlights the need of such tools to facilitate health-related studies. Furthermore, noise estimates from CNOSSOS with relatively coarser input data are compared to the RTN-96 calculated noise, which is one of the noise prediction standards in the Nordic countries.

Our study also has limitations. The use of coarser inputs such as $100 \mathrm{~m}$ CORINE land cover, simplified vehicle composition (LDV, HDV) in noise modelling using CNOSSOS, as compared to the higher quality (and resolution) input data in RTN-96 (as well as air pollution estimation). In addition, with regard to comparison between CNOSSOS and RTN-96, there is a number of differences in input data. All above may explain the lower levels of noise and much lower variation seen for CNOSSOS. Moreover, air pollution contributions from highways are not properly described in $\mathrm{OSPM} \circledast$, as highlighted above. This may also introduce errors in air pollution estimates.

There was an offset of $1 \mathrm{~m}$ between the noise calculation points of the CNOSSOS and the RTN-96. Thus, a comparison of their estimated noise at same address locations was not possible. Lack of measured noise data, due to inherent problems with estimation of noise for validation of modelled values, made it impossible to evaluate CNOSSOS model performance against field measurements. Also, the results presented here are based on air-noise assessments conducted in a relatively small geographical area (both sites), and for selected address locations in a single year 2005 .

\section{Conclusions}

In this study, the spatial relationship of air pollution and noise has been investigated at address level, in the Danish cities of Copenhagen and Roskilde. In conjunction, a tool based on the new AirGIS system (DEHM/UBM/AirGIS) together with the OSPM ${ }^{\circledR}$, and the CNOSSOS has been developed, and used to model exposure to both types of pollution using datasets based on similar geographical structure. Overall, correlations were weak, and moderately stronger at sites in proximity to traffic than background sites. In some cases in Roskilde, air-noise correlations were negative mainly due to the influence of wood burning. In summary, Spearman's rank air-noise correlation varied significantly in the range |0.01-0.42|, which suggests a potential to determine the independent health effects of both stressors.

The background concentrations of air pollution have significant influence on street-level air pollution, and subsequently air-noise relationship in urban settings. However, non-traffic emission sources (e.g. wood burning) also affect associations. Among traffic attributes neither AADT nor traffic speed showed substantial influence on air-noise correlation. Moreover, there were significant differences in CNOSSOS estimated noise, in terms of lower noise levels and much lower variation in predicted noise, as compared to RTN-96 noise estimates in both Copenhagen and Roskilde.

\section{Outlook}

More work needs to be done to (i) further test and evaluate CNOSSOS using higher quality inputs (e.g. 10 m land cover polygons, detailed vehicle composition), and compare its modelled noise with the field measurements to analyse model's feasibility for noise exposure studies in Denmark (ii) address and reduce OSPM ${ }^{\circledR}$ underestimations along highways using specific highway air pollution models.

\section{Funding}

This work was supported by the Graduate School of Science and Technology (GSST) (Project \# 21315), Aarhus University, Denmark; the NPRP award (NPRP \# 7-649-2-241) from the Qatar National Research Fund (a member of The Qatar Foundation); and the Danish Big Data Centre for Environment and Health (BERTHA) funded by the Novo Nordisk Foundation Challenge Programme (Grant \# NNF170C0027864). The statements made in this paper are solely the responsibility of the authors.

\section{CRediT authorship contribution statement}

Jibran Khan: Conceptualization, Data curation, Methodology, Software, Formal analysis, Writing - original draft. Konstantinos Kakosimos: Writing - review \& editing, Funding acquisition, Project administration. Steen Solvang Jensen: Writing - review \& editing, Funding acquisition, Project administration. Ole Hertel: Writing - review \& editing, Funding acquisition, Project administration. Mette Sørensen: Writing - review \& editing, Investigation. John Gulliver: Software, Investigation, Writing - review \& editing. Matthias Ketzel: Writing - review \& editing, Investigation, Funding acquisition, Project administration.

\section{Declaration of competing interest}

The authors declare that they have no known competing financial interests or personal relationships that could have appeared to influence the work reported in this paper.

\section{Appendix A. Supplementary data}

Supplementary data to this article can be found online at https://doi. org/10.1016/j.scitotenv.2020.138577.

\section{References}

Allen, R.W., Davies, H., Cohen, M.A., Mallach, G., Kaufman, J.D., Adar, S.D., 2009. The spatia relationship between traffic-generated air pollution and noise in 2 US cities. Environ. Res. 109 (3), 334-342. https://doi.org/10.1016/j.envres.2008.12.006.

Beelen, R., Hoek, G., Houthuijs, D., van den Brandt, P.A., Goldbohm, R.A., Fischer, P., ... Brunekreef, B., 2009. The joint association of air pollution and noise from road traffic with cardiovascular mortality in a cohort study. Occupational and environmental medicine 66 (4), 243-250.

Berkowicz, R., 2000a. OSPM-a parameterised street pollution model. Urban Air Quality: Measurement, Modelling and Management. Springer, pp. 323-331.

Berkowicz, R., 2000b. A simple model for urban background pollution. Environ. Monit. Assess. 65 (1), 259-267.

Bilenko, N., Rossem, L.v., Brunekreef, B., Beelen, R., Eeftens, M., Hoek, G., ... Koppelman, G.H., 2015. Traffic-related air pollution and noise and children's blood pressure: results from the PIAMA birth cohort study. European journal of preventive cardiology 22 (1), 4-12.

Brandt, J., Silver, J.D., Frohn, L., Geels, C., Gross, A., Hansen, A.B., ... Villadsen, H., 2012. An integrated model study for Europe and North America using the Danish Eulerian Hemispheric Model with focus on intercontinental transport of air pollution. Atmospheric Environment 53, 156-176.

Cai, Y., Zijlema, W.L., Doiron, D., Blangiardo, M., Burton, P.R., Fortier, I., ... Mbatchou, S., 2017. Ambient air pollution, traffic noise and adult asthma prevalence: a BioSHaRE approach. European Respiratory Journal 49 (1), 1502127.

Cai, Y., Hodgson, S., Blangiardo, M., Gulliver, J., Morley, D., Fecht, D., ... Elliott, P., 2018. Road traffic noise, air pollution and incident cardiovascular disease: a joint analysis of the HUNT, EPIC-Oxford and UK Biobank cohorts. Environment international 114, $191-201$.

Christensen, J.H., 1997. The Danish eulerian hemispheric model - a three-dimensional air pollution model used for the arctic. Atmos. Environ. 31 (24), 4169-4191. https://doi. org/10.1016/S1352-2310(97)00264-1.

Danish EPA, 2006. Nord2000: nordic noise prediction method. Retrieved from. https:// eng.mst.dk/air-noise-waste/noise/traffic-noise/nord2000-nordic-noise-predictionmethod/.

Davies, H.W., Vlaanderen, J., Henderson, S., Brauer, M., 2009. Correlation between coexposures to noise and air pollution from traffic sources. Occup. Environ. Med. 66 (5), 347-350.

De Roos, A.J., Koehoorn, M., Tamburic, L., Davies, H.W., Brauer, M., 2014. Proximity to traffic, ambient air pollution, and community noise in relation to incident rheumatoid arthritis. Environ. Health Perspect. (1), 120. 
Ellermann, T., Nygaard, J., Nøjgaard, J.K., Nordstrøm, C., Brandt, J., Christensen, J., Ketzel, M., Massling, A., Bossi, R., Jensen, S.S., 2018. The Danish Air Quality Monitoring Programme. Annual Summary for 2017. Scientific Report from DCE - Danish Centre for Environment and Energy No. 281Aarhus University, DCE - Danish Centre for Environment and Energy 83 pp. Retrieved from. http://dce2.au.dk/pub/SR281.pdf.

Euoropean Environment Agency (EEA), 2017. Road traffic remains biggest source of noise pollution in Europe. Retrieved from. http://www.eea.europa.eu/highlights/road-traffic-remains-biggest-source/?utm_medium=email\&utm_campaign=

NoisePollution\&utm_content $=$ NoisePollution + CID_

24a9ddf571cad239903cb68f54679281\&utm_source=EEA\%20Newsletter\&utm_ term $=$ Read\%20more.

European Commission, 2016a. Common noise assessment methods for Europe (CNOSSOS-EU): implementation challenges in the context of EU noise policy developments and future perspectives. Retrieved from. https://ec.europa.eu/jrc/en/publication/common-noise-assessment-methods-europe-cnossos-eu-implementationchallenges-context-eu-noise-policy.

European Commission, 2016b. Air Quality and Noise Legislation. Retrieved from. http://ec europa.eu/environment/legal/law/5/e_learning/module_1_5.htm.

European Commission, 2016c. Links between noise and air pollution and socioeconomic status. Retrieved from. http://ec.europa.eu/environment/integration/research/ newsalert/pdf/air_noise_pollution_socioeconomic_status_links_IR13_en.pdf.

European Commission Working Group Assessment of Exposure to Noise (WG-AEN) 2007. Good Practice Guide for Strategic Noise Mapping and the Production of Associated Data on Noise Exposure. Retrieved from. https://www.lfu.bayern.de/laerm/eg umgebungslaermrichtlinie/doc/good_practice_guide_2007.pdf.

European Environment Agency (EEA), 2019. Air quality in Europe. Retrieved from. https://www.eea.europa.eu/publications/air-quality-in-europe-2019.

Eze, I.C., Foraster, M., Schaffner, E., Vienneau, D., Héritier, H., Rudzik, F., ... Schindler, C. 2017. Long-term exposure to transportation noise and air pollution in relation to incident diabetes in the SAPALDIA study. International journal of epidemiology 46 (4), $1115-1125$.

Fecht, D., Hansell, A.L., Morley, D., Dajnak, D., Vienneau, D., Beevers, S., ... Gulliver, J., 2016. Spatial and temporal associations of road traffic noise and air pollution in London: Implications for epidemiological studies. Environment international 88, 235-242.

Foraster, M., Deltell, A., Basagaña, X., Medina-Ramón, M., Aguilera, I., Bouso, L., ... Slama, R. 2011. Local determinants of road traffic noise levels versus determinants of air pollution levels in a Mediterranean city. Environmental Research 111 (1), 177-183.

Gan, W.Q., Davies, H.W., Koehoorn, M., Brauer, M., 2012. Association of long-term exposure to community noise and traffic-related air pollution with coronary heart disease mortality. Am. J. Epidemiol. 175 (9), 898-906.

Gracey Associates UK, 2017. Frequency Weightings: Definitions, Terms, Units, Measurements. Retrieved from. http://www.acoustic-glossary.co.uk/frequency-weighting htm?zoom_highlight $=\mathrm{A}+$ weighting.

Hvidtfeldt, U.A., Ketzel, M., Sørensen, M., Heretl, O., Khan, J., Brandt, J., Raaschou-Nielsen, O., 2018. Evaluation of the Danish AirGIS air pollution modelling system against measured concentrations of PM2.5, PM10 and black carbon. Environ. Epidemiol. 2 (2), e014

International Electrotechnical Commission (IEC 61672-1), 2013. Electroacoustics - sound level meters - part 1: specifications. Retrieved from. https://webstore.iec.ch/publication $/ 5708$.

Jensen, S.S., Berkowicz, R., Hansen, H.S., Hertel, O., 2001. A Danish decision-support GIS tool for management of urban air quality and human exposures. Transp. Res. Part D: Transp. Environ. 6 (4), 229-241.

Jensen, S.S., Hvidberg, M., Petersen, J., Storm, L., Stausgaard, L., Becker, T., Hertel, O., 2009. GIS-based National Road and Traffic Database (1960-2005). National Environmental Research Institute, Aarhus Universitet, Roskilde. 73 s. Report No. 678, 2009. http:// www2.dmu.dk/Pub/FR678.pdf.

Jensen, S.S., Ketzel, M., Becker, T., Christensen, J., Brandt, J., Plejdrup, M., ... Ellermann, T., 2017. High resolution multi-scale air quality modelling for all streets in Denmark. Transportation Research Part D: Transport and Environment 52, 322-339.

Jensen, S.S., Plejdrup, M.S., Hilling, K., 2019. GIS-based National Road and Traffic Database 1960-2020. Aarhus University, DCE - Danish Centre for Environment and Energy 25 pp - Technical Report No. 151. http://dce2.au.dk/pub/TR151.pdf.

Jonasson, H.G. 2006. Acoustic source modelling of Nordic road vehicles - SP Swedish National Testing and Research Institute Report 2006:12. Retrieved from Borås, Sweden. http://www.vejdirektoratet.dk/DA/vejsektor/forskning-og-udvikling/Miljovenlige\% 20veje/Stoj/NORD2000/Documents/PDF\%20til\%20st\%C3\%B8jtema/155950.pdf.

Jonasson, H., Nielsen, H., 1996. Road Traffic Noise-Nordic Prediction Method. Nordic Council of Ministers, Tema Nord, Copenhagen, Denmark, p. 1996525.

Kakosimos, K.E., Hertel, O., Ketzel, M., Berkowicz, R., 2010. Operational street pollution model (OSPM)-a review of performed application and validation studies, and future prospects. Environ. Chem. 7 (6), 485-503.

Kephalopoulos, S., Paviotti, M., 2016. Common noise assessment methods for Europe (CNOSSOS-EU): implementation challenges in the context of EU noise policy developments and future perspectives. Retrieved from. https://ec.europa.eu/jrc/en/publication/common-noise-assessment-methods-europe-cnossos-eu-implementationchallenges-context-eu-noise-policy.

Kephalopoulos, S., Paviotti, M., Ledee, F.A., 2012. Common Noise Assessment Methods in Europe (CNOSSOS-EU). (pp. 180 p). Publications Office of the European Union.

Khan, J., Ketzel, M., Kakosimos, K., Sørensen, M., Jensen, S.S., 2018. Road traffic air and noise pollution exposure assessment - a review of tools and techniques. Sci. Total Environ. 634, 661-676. https://doi.org/10.1016/j.scitotenv.2018.03.374.

Khan, J., Kakosimos, K., Raaschou-Nielsen, O., Brandt, J., Jensen, S.S., Ellermann, T., Ketzel, M., 2019. Development and performance evaluation of new AirGIS-A GIS based air pollution and human exposure modelling system. Atmos. Environ. 198, 102-121. https://doi.org/10.1016/j.atmosenv.2018.10.036.
King, E., Bourdeau, E., Zheng, X., Pilla, F., 2016. A combined assessment of air and noise pollution on the High Line, New York City. Transp. Res. Part D: Transp. Environ. 42, 91-103.

Kokkonen, J., Kontkanen, O., Maijala, P.P., 2016. CNOSSOS-EU noise model implementation in Finland. Paper Presented at the Baltic-Nordic Acoustic Meeting.

Kragh, J., 2011. Traffic noise prediction with Nord2000-an update. Paper Presented at the Proceedings of ACOUSTICS.

Larsson, K., 2016. Updated road traffic noise emission models in Sweden. Paper Presented at the INTER-NOISE and NOISE-CON Congress and Conference Proceedings.

Linares, C., Díaz, J., Tobías, A., Miguel, J.D., Otero, A., 2006. Impact of urban air pollutants and noise levels over daily hospital admissions in children in Madrid: a time series analysis. Int. Arch. Occup. Environ. Health 79 (2), 143-152.

Maijala, P., Kontkanen, O., 2016. CNOSSOS-EU sensitivity to meteorological and to some road initial value changes. Paper Presented at the INTER-NOISE and NOISE-CON Congress and Conference Proceedings.

Morley, D. W., de Hoogh, K., Fecht, D., Fabbri, F., Bell, M., Goodman, P. S., ... Gulliver, J. (2015). International scale implementation of the CNOSSOS-EU road traffic noise prediction model for epidemiological studies. Environ. Pollut., 206, 332-341. doi:https:// doi.org/10.1016/j.envpol.2015.07.031.

Mueller, N., Rojas-Rueda, D., Basagaña, X., Cirach, M., Cole-Hunter, T., Dadvand, P., Martinez, D., 2017. Urban and transport planning related exposures and mortality: a health impact assessment for cities. Environ. Health Perspect. 125 (1), 89-96.

National Centre for Atmospheric Research (NCAR), 2018. Weather Research and Forecasting (WRF) Model. Retrieved from. https://www.mmm.ucar.edu/weather-researchand-forecasting-model.

Nieuwenhuijsen, M.J., 2015. In: Nieuwenhuijsen, M.J. (Ed.), Exposure assessment in environmental epidemiology, Second ed. Oxford University Press, New York, US

Nieuwenhuijsen, M., Gascon, M., Martinez, D., Ponjoan, A., Blanch, J., Garcia-Gil, M., Espinosa, A., 2018. Air pollution, noise, blue space, and green space and premature mortality in Barcelona: a mega cohort. Int. J. Environ. Res. Public Health 15 (11), 2405

NoiseMeters Inc, 2017. Frequency Weightings - A-Weighted, C-Weighted or Z-Weighted? . Retrieved from. https://www.noisemeters.com/help/faq/frequency-weighting.asp

Pitchika, A., Hampel, R., Wolf, K., Kraus, U., Cyrys, J., Babisch, W., Schneider, A., 2017. Longterm associations of modeled and self-reported measures of exposure to air pollution and noise at residence on prevalent hypertension and blood pressure. Sci. Total Environ. 593, 337-346.

Plejdrup, M., Gyldenkærne, S., 2011. Spatial distribution of emissions to air - the SPREAD model. Retrieved from. http://www.dmu.dk/Pub/FR823.pdf.

PostGIS Development Group, 2018. PostGIS - spatial and geographic objects for PostgreSQL. Retrieved from. https://postgis.net/.

PostgreSQL Global Development Group, 2018. PostgreSQL: the world's most advanced open source relational database. Retrieved from. https://www.postgresql.org/.

Pyko, A., Eriksson, C., Lind, T., Mitkovskaya, N., Wallas, A., Ögren, M., Pershagen, G., 2017. Long-term exposure to transportation noise in relation to development of obesity-a cohort study. Environ. Health Perspect. 125 (11), 117005

R Core Team, 2020. R: A Language and Environment for Statistical Computing. Retrieved from. https://www.r-project.org/.

Shu, S., Yang, P., Zhu, Y., 2014. Correlation of noise levels and particulate matter concentrations near two major freeways in Los Angeles, California. Environ. Pollut. 193, 130-137.

Smith, R.B., Fecht, D., Gulliver, J., Beevers, S.D., Dajnak, D., Blangiardo, M., Anderson, H.R., 2017. Impact of London's road traffic air and noise pollution on birth weight: retrospective population based cohort study. Bmj 359, j5299.

Sørensen, M., Lühdorf, P., Ketzel, M., Andersen, Z.J., Tjønneland, A., Overvad, K., RaaschouNielsen, O., 2014. Combined effects of road traffic noise and ambient air pollution in relation to risk for stroke? Environ. Res. 133, 49-55. https://doi.org/10.1016/j. envres.2014.05.011.

Stansfeld, S.A., 2015. Noise effects on health in the context of air pollution exposure. Int. J. Environ. Res. Public Health 12 (10), 12735-12760.

Statistics Denmark, 2016. By1: population 1. January by urban areas, age and sex. Retrieved from. http://www.statbank.dk/BY1.

Statistics Denmark, 2018. Regioner, landsdele og kommuner. Retrieved from. https:// www.dst.dk/da/Statistik/dokumentation/nomenklaturer/regioner-landsdele-ogkommuner

Tang, U.W., Wang, Z.S., 2007. Influences of urban forms on traffic-induced noise and air pollution: results from a modelling system. Environ. Model Softw. 22 (12), 1750-1764. https://doi.org/10.1016/j.envsoft.2007.02.003.

Tenailleau, Q.M., Bernard, N., Pujol, S., Parmentier, A.-L., Boilleaut, M., Houot, H., Mauny, F., 2016. Do outdoor environmental noise and atmospheric NO2 levels spatially overlap in urban areas? Environ. Pollut. 214, 767-775. https://doi.org/ 10.1016/j.envpol.2016.04.082.

Tobías, A., Díaz, J., Saez, M., Alberdi, J.C., 2001. Use of Poisson regression and Box-Jenkins models to evaluate the short-term effects of environmental noise levels on daily emergency admissions in Madrid, Spain. Eur. J. Epidemiol. 17 (8), 765-771.

Van Kempen, E.E.M.M., Casas, M., Pershagen, G., Foraster, M., 2017. Cardiovascular and metabolic effects of environmental noise: systematic evidence review in the framework of the development of the WHO environmental noise guidelines for the European Region. Retrieved from. https://rivm.openrepository.com/bitstream/handle/10029/620941/2017-0078.pdf? sequence $=1$ \&isAllowed $=\mathrm{y}$.

Van Kempen, E., Casas, M., Pershagen, G., Foraster, M., 2018. WHO environmental noise guidelines for the European region: a systematic review on environmental noise and cardiovascular and metabolic effects: a summary. Int. J. Environ. Res. Public Health 15 (2), 379.

Vardoulakis, S., Fisher, B.E., Pericleous, K., Gonzalez-Flesca, N., 2003. Modelling air quality in street canyons: a review. Atmos. Environ. 37 (2), 155-182. 
Vienneau, D., Héritier, H., Foraster, M., Eze, I.C., Schaffner, E., Thiesse, L., Brink, M., 2019. Façades, floors and maps-influence of exposure measurement error on the association between transportation noise and myocardial infarction. Environ. Int. 123, 399-406.

Weber, S., 2009. Spatio-temporal covariation of urban particle number concentration and ambient noise. Atmos. Environ. 43 (34), 5518-5525.

Weber, S., Litschke, T., 2008. Variation of particle concentrations and environmental noise on the urban neighbourhood scale. Atmos. Environ. 42 (30), 7179-7183. https://doi. org/10.1016/j.atmosenv.2008.05.047.
Weber, N., Haase, D., Franck, U., 2014. Assessing modelled outdoor traffic-induced noise and air pollution around urban structures using the concept of landscape metrics. Landsc. Urban Plan. 125, 105-116. https://doi.org/10.1016/j. landurbplan.2014.02.018.

Zock, J.-P., Verheij, R., Helbich, M., Volker, B., Spreeuwenberg, P., Strak, M., Groenewegen, P., 2018. The impact of social capital, land use, air pollution and noise on individual morbidity in Dutch neighbourhoods. Environ. Int. 121, 453-460. 